\title{
Орбитална киста, произхождаща от респираторен епител, в резултат на стара назо-орбито-етмоидална фррактура
}

Respiratory Epithelial Lined Orbital Cyst in Result of the Old Naso-Orbital-Ethmoid Fracture

\author{
Цв. Тончев, М. Милков \\ УМБАЛ "Св. Марина" - Варна \\ Специализирана УНГ-клиника "Св. Петка" - Варна \\ Dr. Tsvetan Tonchev, DMD, PhD \\ Dr. M. Milkov
}

Abstract

Posttraumatic orbital cysts originating from respiratory epithelium are extremely rare just like the cases with mucocele of the orbit. The author presents a case of exteriorized orbital cyst originating from respiratory epithelium in a result of an old nasal-orbital-ethmoidal fracture. The article describes the sequence in preparation and treatment, and reviews the literature regarding this problem.

Key words: Orbit; Naso-orbital-ethmoid fracture; Orbital cyst; Mucocoele; Respiratory epithelium.

\section{Резюме}

Посттравматичните орбитални кисти, произхождаши от респираторен епител, са изключително редки, подобно на случаите с мукоцеле на орбитата. Представен е случай с екстериоризирала орбитална киста, произхождаща от респираторен епител, в резултат на стара назо-орбито-етмоидална фрактура. Описана е последователността на подготовката и лечението, като е направен преглед на литературата по този проблем.

Ключови думи: орбита; назо-орбито-етмоидална фрактура; орбитални кисти; мукоцеле; респираторен епител.

\section{Увод}

Най-често срещаните кистозни образувания в областта на орбитата са дермоидните и епидермоидните кисти (1). Възникването на епителни кисти на орбитата е резултат на хамартомни включвания или на предшестваща травма на околоносните кухини. Хамартомите могат да произхождат от конюнктивата, тъканите на лакрималната система, лещата, костна, мастна или мозъчна тъкан $(1 ; 2)$. Локализацията на мукоцелето извън синусите, в орбитата и ендокраниума е рядка, като често при хистологичното изследване се откриват участьци с епителни включвания в стената $(3 ; 4)$. Като причина за възникването се дискутират обикновено или алергично възпаление на околоносните кухини и носната лигавица, включително назална полипоза; туморни процеси в областта на канала или отвора на синуса, и разбира се, определен процент от случаите, при които етиологията остава неизяснена $(5 ; 6 ; 7)$. Травмата като етиологичен фактор се свързва с разместване на костни фрагменти, водещи впоследствие до обструкция на дренажа на синусната кухина и миграция на епител към орбитата $(8 ; 9)$. Тя е често споменаван момент като причина както при мукоцелето, така и при епителните орбитални кисти, но за съжаление не са много описаните случаи с подобна взаимовръзка (4).

\section{Цел}

Описание на оперативното лечение при пациент с екстериоризирала етмоидална киста в резултат на стара травма в назо-орбито-етмоидална област отпреди повече от двадесет години. 


\section{Описание на случая}

Към отделението по лицево-челюстна хирургия беше насочена пациентка на 50 години от Дом за възрастни с психични разстройства, където се лекува от дълги години. В момента на представяне в болницата се установява наличие на кистозна формация, разположена медиално от лявата очна цепка. Същата е на широка основа, ангажираща кожата медиално, без да е възможно клинично да се определи граница в дълбочина (Фиг. 1).

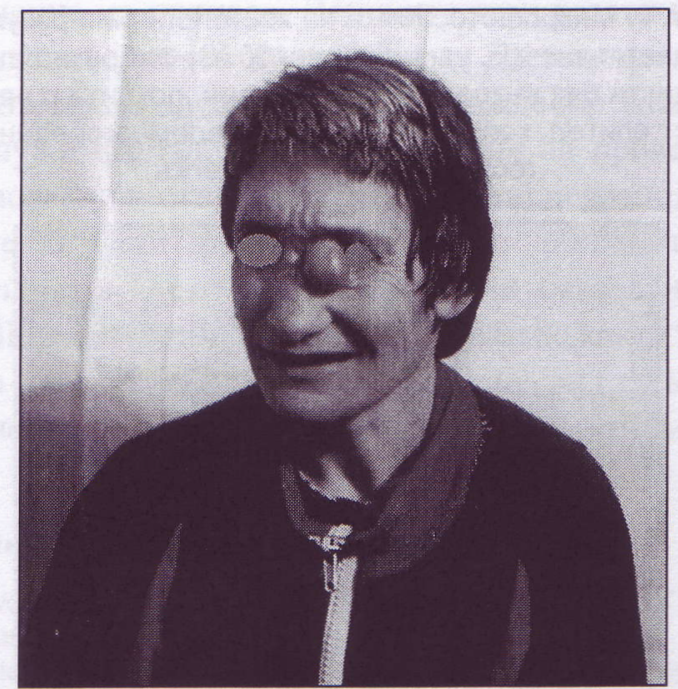

Фиг. 1. Вид на болната преди операцията

При огледа също прави впечатление наличието на стар цикатрикс в областта на носа и посттравматичният телекантус, дължащ се най-вероятно на нелекувана назо-орбито-етмоидална фрактура при инцидент в миналото (Фиг. 2). Преди около двадесет години при неясни обстоятелства получила травма в областта на основата на носа с проникващо нараняване в дълбочина от остър предмет. Раната е обработена в дома без допълнителни консултации и образни изследвания. От около 7-8 години е забелязано подуване в областта на горномедиален квадрант на лявата орбита, което бавно нараствало.

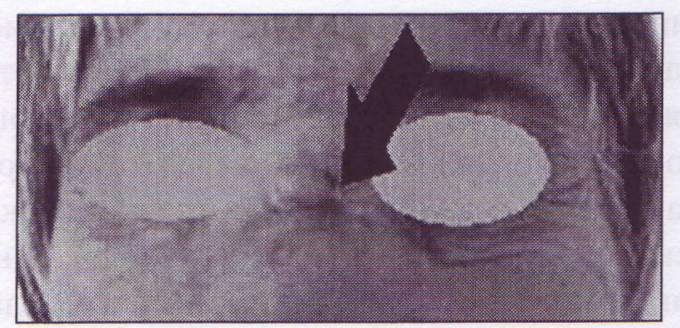

Фиг. 2. Мястото на цикатрикса е посочено със стрелка. Използвана е снимка след операцията.
От направената КАТ се установи наличие на псевдокистична лезия с диаметър около 26 мм, разположена медиално и пред очния булб, която в дълбочина се проследява за етмоидалните клетки. Костните структури на предната черепна ямка са интактни. Изследването беше насочено конкретно с цел изключване на интракраниална комуникация (Фиг. 3).

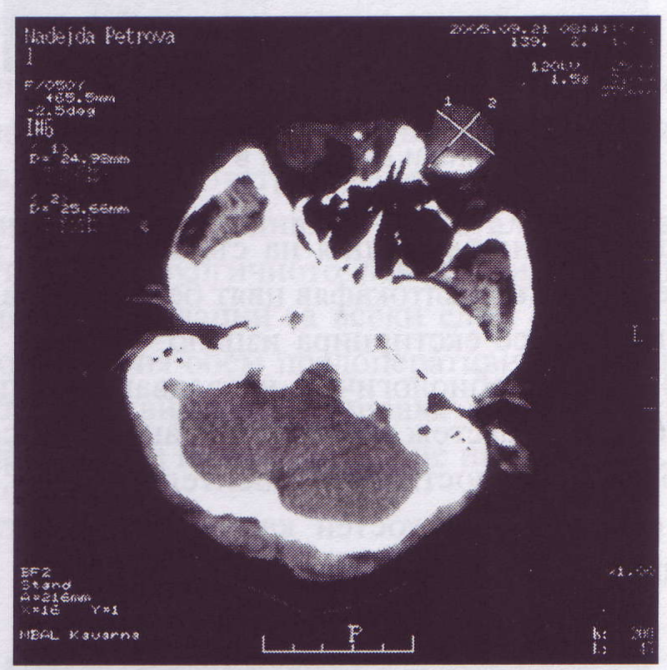

Фиг. 3. КАТ, показваща псевдокистична лезия, разположена в медиален очен ъгъл вляво

Оперативното лечение се проведе след предварителна подготовка под обща анестезия. С модифицирана инцизия по Lynch медиално от формацията същата се отдели от надлежащата кожа, след което строго екстракапсуларно се продължи дисекцията в дълбочина (Фиг. 4). Тъканите на орбитата се екартираха латерално, като се идентифицираха медиалният клепачен лигамент и слъзната торбичка, които се съхраниха (Фиг. 5).

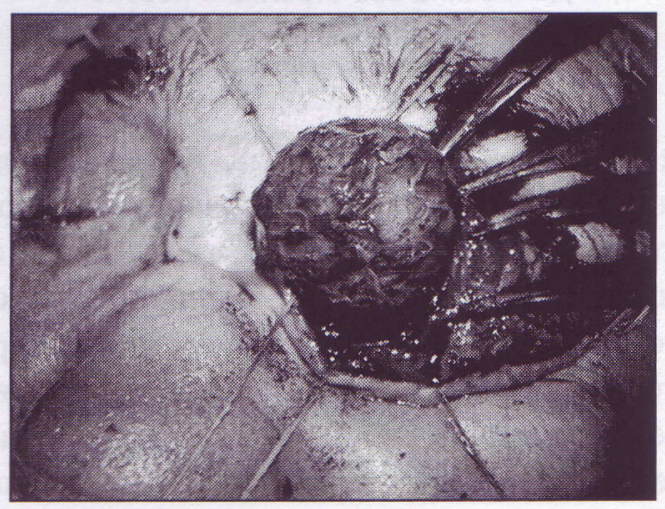

Фиг. 4. Отпрепариране на надлежащата кожа от формацията 


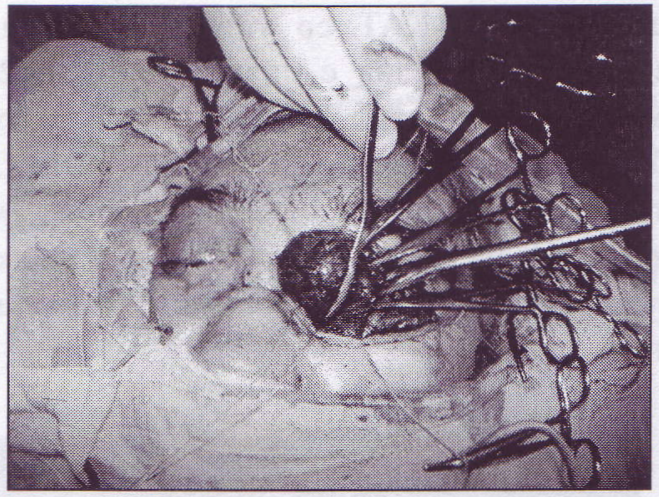

Фиг. 5. Екартиране тъканите на орбитата латерално и дисекция в дълбочина

След частична евакуация на съдържимото, което беше с мръсно жълтокафяв цвят без миризма, кистозният сак се екстирпира изцяло. Взетият материал за микробиологично изследване не показа бактериален растеж. Отпрепарирането на сака в дълбочина се постигна относително лесно, като той се отдели от костен кавитет в областта на предни етмоидални клетки (Фиг. 6).

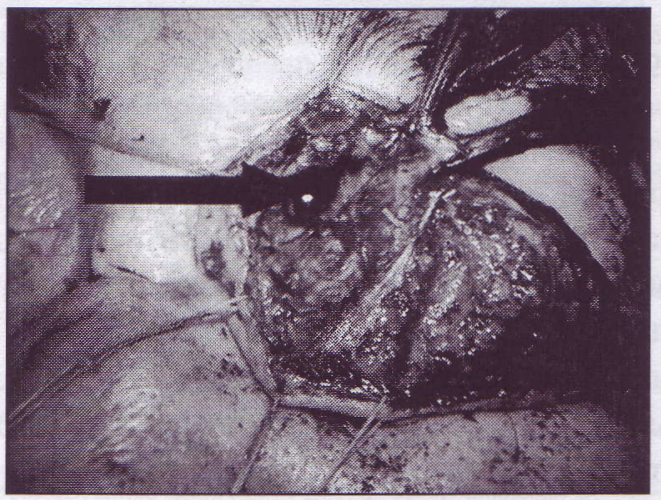

Фиг. 6. Интраоперативен изглед след отстраняване на формацията.

В дълбочина със стрелка е посочена костната кавитация в областта на предните етмоидални клетки

След ексцизия на излишната кожа се пристъпи към послойно възстановяване на дефекта. Хистологичното изследване показа фиброзна стена на киста без възпалителни промени, покрита с ресничест епител, който на места е псевдомногореден и с гоблетови клетки (Фиг. 7). Следоперативният период протече спокойно, болната беше изписана на десетия следоперативен ден без усложнения. На контролния преглед след три месеца се констатира задоволителен естетичен резултат без данни за нарушена зрителна острота или ограничение в обема движения от страна на окото (Фиг. 8).

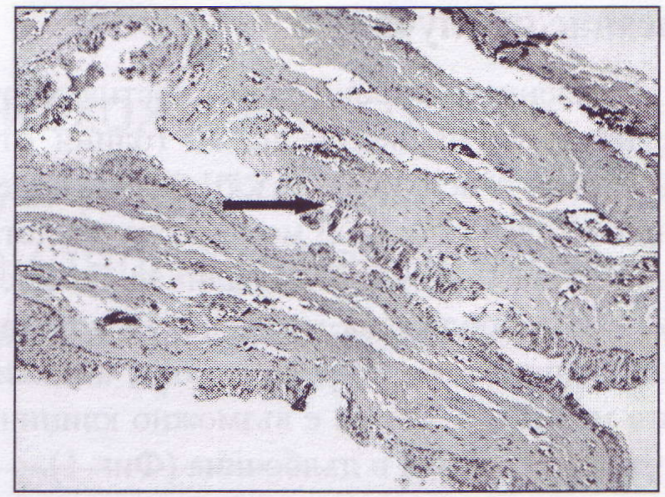

Фиг. 7. Микрофотоснимка на хистологичния резултат (Оцветяване XE, увеличение 100 X): Фиброзна стена на киста без възпалителни промени, покрита с ресничест епител, който на места е псевдомногореден и с гоблетови клетки (стрелка).

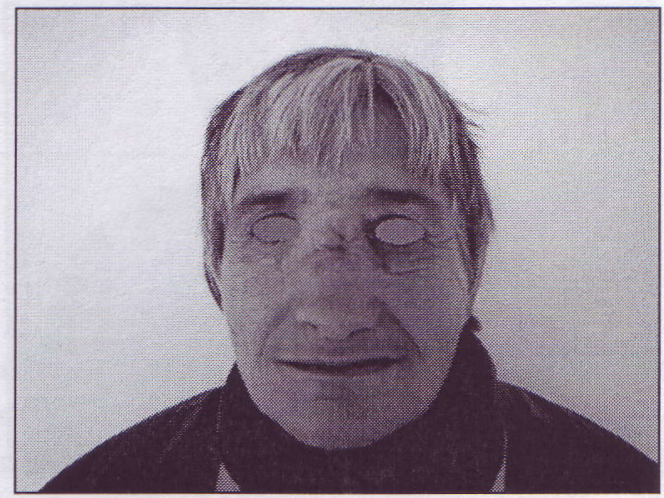

Фиг. 8. Следоперативен резултат три месеца след операцията

\section{Дискусия}

Епителните кисти на орбитата са резултат на хамартомни включвания или на предшестваща травма на околоносните кухини. Тяхното възникване след травма и хистологичната картина показва пряката клиникопатологична връзка с епитела на околоносните кухини. Орбиталното мукоцеле може да започне своето развитие след нарушаване целостта на периорбиталните синуси. Травма, възпаление, пространство заемащите процеси като полипи и остеоми могат да доведат до обструкция на синусния дренаж, както и анатомични аномалии в областта. В нашия случай се касае за кистозна лезия с клиничните характеристики на мукоцеле, която хистологично е представена от фиброзна стена на киста без възпалителни промени, покрита с ресничест епител, който на места е псевдомногореден. Връзката на лезията с предните етмоидални клетки е доказана компютъртомографски и клинично (Фиг. 3; Фиг. 6). Най-вероятната причина за възникването е предшестващата травма. Ние смятаме, че е възможен следният механизъм за 
възникване на кистичната лезия: след травмата се е получило разместване на костни фрагменти на предните етмоидални клетки, в резултат на което се е получила дренажна обструкция, довела до възникването на ретенционна киста от описания тип. Това вероятно е било опосредствано и от неминуемо възникналия кръвоизлив, който впоследствие е довел до фиброзиране и сраствания в областта. При първично нарушената цялост на синусната стена към орбитата това е посоката с възможно най-малко съпротивление за разпространение на процеса. Всичките тези разсъждения и изводите, които правим, имат преимуществено хипотетичен характер. В потвърждение може да послужи фактът, че липсват данни за проведени изследвания относно случаите на неразпознати и нелекувани фрактури на назо-орбито-етмоидалния комплекс в достъпната ни база данни в Medline. Причина за това може да бъде както трудната диагностика на този тип фрактури (задължително използване на КАТ), така и безсимптомното

\section{Литература}

1. West J, Drewe R, McNab A. Atypical choristomatous cysts of the orbit. Aust. N. Z. J. Ophthalmol. 1997; 25: 117-23.

2. Mee J, McNab A, McKelvie P. Respiratory epithelial orbital cysts. Clin Experiment Ophthalmol. 2002 Oct; 30(5): 356-60.

3. Rootman J, Steward B, Goldberg R, et al: Orbital surgery: a conceptual approach. Philadelphia, Lippincott-Raven Publisher, 1995; p. 52.

4. James C, Lyness R, Wright J. Respiratory epithelium lined cysts presenting in the orbit without associated mucocoele formation. Br. J. Ophthalmol. 1986; 70: 387-90.

5. Busaba N, Salman S: Maxillary sinus mucoceles: Clinical presentation and long-term results of endoscopic surgical treatment. Laryngoscope; 1999, 109: 1446-1449.

\section{Адрес за кореспонденция:}

Д-р Цветан Тончев, д.м. Медииински университет - Варна Факултет по дентална медичина, Катедра по ОЛЧХ ул. “Марин Дринов" № 55, 9002 Варна E-mail: mfstonchev@mu-varna.bg протичане на по-леките травми. Наличието на стерилна посявка от направеното микробиологично изследване изключва възможността за възпалителна генеза при нашия случай в резултат на абсцес или пиоцеле. Естествено динамичната оценка на обема нарастване във времето е невъзможна, предвид трудностите в анамнезата, което не дава възможност за екзактна преценка.

\section{Изводи}

Оптималният изход от оперативното лечение при случаите с орбитални кисти, както и мукоцеле е пълното им отстраняване, изключващо възможността за рецидив от резидуални лигавични участъци. Хирургичното лечение изисква пълни анамнестични данни за всеки един случай, както и необходимия обем предоперативни изследвания с оглед правилна планировка на оперативната интервенция и предотвратяване на изненади.

6. Marks S, Latoni J, Mathog R: Mucoceles of the maxillary sinus. Otolaryngology Head and Neck Surgery; 1997, 117:18-21.

7. Chandra A, Lim M, Scott E, Morsman D: Frontoethmoidal mucocele associated with bilateral increased intraocular pressure and proptosis. Can J Ophthalmol. 2007; 42(1): 143-4.

8. Eggert J, Harris G, Caya J. Respiratory epithelial cyst of the orbit. Ophthal. Plast. Reconstr. Surg. 1988; 4: 101-4.

9. Morris W, Fleming J. Respiratory choristomatous cysts in the temporal orbit. Ophthal. Plast. Reconstr. Surg. 2001; 17: 462-4.

\section{Address for correspondence:}

Dr. Tsvetan Tonchev, DMD, PhD Medical University Varna Faculty of Dental Medicine, Department of OMFS 55 Marin Drinov st., 9002 Varna, Bulgaria

E-mail:mfstonchev@mu-varna.bg drnedev@abv.bg 